https://doi.org/10.15407/ujpe64.11.977

L. JENKOVSZKY

Bogolyubov Institute for Theoretical Physics, Nat. Acad. of Sci. of Ukraine (14b, Metrolohichna Str., Kyiv 03143, Ukraine; e-mail: jenk@bitp.kiev.ua)

\title{
FROM EUCLID TO BGL ${ }^{1}$
}

\begin{abstract}
The emergence of the new non-Euclidean geometry of Bolyai, Gauß, and Lobachevskii (BGL) and its impact on modern sciences is the subject of a series of biennial conferences. Below, I briefly review the history.

Keywords: non-Euclidean geometry, Bolyai, Gauß, Lobachevskii (BGL).
\end{abstract}

\section{Prologue}

Over 2300 years ago, the great Greek mathematician Eukleides $(E v \kappa \lambda \varepsilon i \delta \eta \zeta$ in Greek, Euclides in Latin; in modern literature, the name is usually written as Euclid, with "c"; I follow the latter spelling) from Alexandria (now Egypt) has laid down the foundation of the geometry now known from textbooks. It was based on a number of postulates and axioms. All but one were generally accepted either as obvious or logically consistent. Exceptional was the 5-th postulate about parallel lines. The proof of this postulate has been an embarrassment ever since Euclidean geometry was founded, although the geometry was not questioned. It was accepted, among others, by Isaac Newton, Leonardo da Vinci, Galileo Galilei, Johann Kepler, Joseph-Louis Lagrange, and Immanuel Kant.

It was only in the first half of the XIX-th century that three great men, J. Bolyai, J.C.F. Gauß, and N.L. Lobachevskii (BGL, alphabetically, Fig. 1) simultaneously and independently revealed the truth.

These developments and the personal dramas of their protagonists - BGL, Fig. 1, motivated the organization of a conference on Non-Euclidean Geometry and its implications in physics and mathematics in 1997 in Uzhgorod, Ukraine. The success of the conference inspired the organizers to continue: BGL became a series of biennial confer-

(C) L. JENKOVSZKY, 2019

ISSN 2071-0194. Ukr. J. Phys. 2019. Vol. 64, No. 11 ences, held at various places connected with the names of the founders of the New Geometry. The main organizer of the series of conferences was the Bogolyubov Institute for Theoretical Physics, National Academy of Sciences of Ukraine. Among its founders and active supporters were Academician István Lovas (Budapest), Professors Elemér Kiss (Marosvásárhely), N.A. Chernikov (Dubna) and G.M. Polotovskii (N. Novgorod) - experts on the subject. The history of the series can be traced at: https://indico.cern.ch/event/586799/page/8964former-bgl-conferences and in Ref. [2]. The success of this series of meetings to a large extent is due to the right choice of the subject, the cast and style ("key") of the conferences uniting physics, mathematics, history, and relevant people coming both from East and West.

\section{Predecessors}

By mentioning the fifth postulate last, Euclid himself, in this way, alluded to a deficiency. A great number of Greek, Arabic, Renaissance, and other mathematicians tried to prove, disprove, generalize, or replace the postulate under question. Interest in geometry was enhanced in the 17-th and 18-th centuries preparing the great harvest in the 19-th century.

\footnotetext{
1 This work is based on the results presented at the XI BolyaiGauss-Lobachevskii (BGL-2019) Conference: Non-Euclidean, Noncommutative Geometry and Quantum Physics.
} 


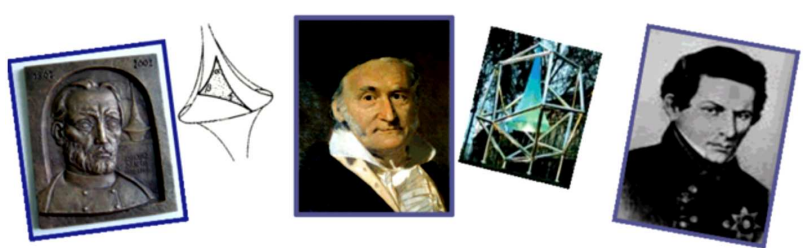

Fig. 1. J. Bolyai, J.C.F. Gauß, and N.I. Lobachevskii
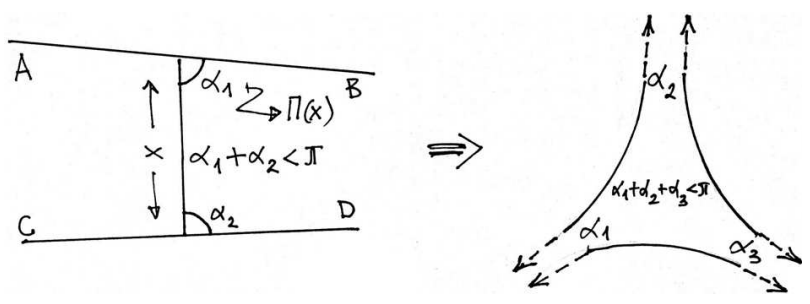

Fig. 2. Visualizing the non-Euclidean geometry

Before BGL, at least two men came close to the concept of the new geometry. One was Girolamo Saccheri, an Italian monk, who made the right step in his "Logica demonstratica" to resolve the contradiction. The idea was further elaborated in his paper entitled "Euclides ab omni naevo vindicates" ("Euclides free of any shadow"), published in 1697. Saccheri's work did not remain unnoticed: it became familiar, e.g., in Göttingen due to the thesis of Klügel (a student of Prof. A. Köstner) "Conatuum praecipurum theoriam parallelarum demonstrandi recensio"), where it was thoroughly reviewed. Later on, in 1766, Saccheri's approach was further developed by Lambert.

Between 1807 and 1816, Schweikert, a German lawyer in Kharkov (sic!), developed his version of non-Euclidean geometry, called "Astralische Geometrie" (alluding to cosmic scales at which any departure from the Euclidean geometry may be noticeable). Schweikart, an amateur mathematician, did not use any formalism, his ideas were mathematically formalized by his nephew Taurinos, who in 1826 published his "Geometria prima elementa", in which the "log-spherical" formalism, preceding that of Bolyai and Lobachevskii was used to prove Euclid's 5-th postulate.

Gauß was familiar with the work of Schweikert and Taurinos.

\section{Bolyai, Gauß, and Lobachevskii (BGL)}

In the new geometry, the sum of internal angles is not $\pi$ any more (Fig. 2). It can be smaller depending on the length of the sides. The new "parallelism angle" $\Pi(x)$ (equivalent of $\pi / 2$ in the Euclidean case) is related to the distance $x$, see Fig. 2, by

$\operatorname{ctg} \Pi(x) / 2=q^{x}$,

where $q$ is a parameter.

The curvature in the right panel of Fig. 2 is accentuated (enhanced) for pedagogical reasons. J. Bolyai, C.F. Gauß, and N.I. Lobachevskii were aware of the non-observability of any departure from the Euclidean geometry within the visible Universe. This yields the epithet "new" ("absolute", "imaginary", "pan", ...) and the reason why contemporaries were so reluctant to accept the apparently abstract construction.

It is like a mystery how a problem open for millennia could have been resolved practically simultaneously (within a decade) independently by three men who never met and did not communicate, see their (simplified) world lines, last Section.

\subsection{Johann Carl Friedrich Gauß}

The eldest among BGL was born in April 30, 1777 in Braunschweig [4]. In 1795, he entered the Göttingen University, where Farkas Bolyai (János' farther) became his closest friend during his studies. After 3 years in Göttingen, Farkas returned to his homeland Transilvania, where he became a teacher of mathematics in Marosvásárhely. The friendship between Farkas and Carl Friedrich however lasted for decades with an extensive exchange of letters, providing valuable information for the history of science.

In 1804, Farkas sent his "proof" of the 5-th postulate to Gauß. In his reply, Gauß indicated an error in the derivation of his friend, adding that himself he also hopes to progress in solving the problem. It looks surprising that Gauß, commenting Lobachevskii's "Geometrische Untersuchungen", wrote to Schumacher in 1846 that he found in Lobachevskii's work "nothing new".

In 1815 in a comment on Mätternik's book, he wrote: "...we should admit that we are unable to advance compared to the 2 thousands years old Euclides". Moreover, in a letter to Olbers (28.04.1817), he wrote that "geometry cannot be proven by human intelligence".

Schweikert published his paper on parallels "Astralische Geometrie" in 1807 and developed it further after he moved from Kharkov to Marburg. Gauß' 
work was inspired to a large extent by a letter of Schweikert in 1819, in which Schweikert informed Gauß of his geometry. Taurinos continued his work in 1924 in close touch with Gauß. As mentioned above, Schweikert and Taurinos stopped half-way, unable to abandon the Euclidean way of reasoning.

After 1816, Gauß, partly inspired by practical goals, started working on geodesics, and, in 1828, he published his famous paper on differential geometry (curved spaces). However, it was only E. Beltrami who in 1868 suggested the interpretation of nonEuclidean geometry in terms of surfaces with negative curvature.

In 1832, Gauß became aware of the work by János Bolyai, mediated by Farkas, and he acknowledged Lobachevskii's "Geometrische Untersuchnungen" in 1840. The same year, he started learning Russian; A.S. Pushkin's "Boris Godunov" in original Russian was found in his library.

Gauß did not publish a single paper on non-Euclidean geometry. On various occasions, e.g., in his letters, he privately praised both Lobachevskii and János Bolyai for their contributions in developing the new geometry, but he never cited them publicly for that achievement! In 1842, Lobachevskii was nominated Member of the Göttingen Scientific Society. However, in Gauß' recommendation, Lobachevskii's work on geometry was not mentioned.

\subsection{Nikolai Ivanovich Lobachevskii}

was born in Nizhni Novgorod (where N.N. Bogolyubov was also born, by the way) on November 20, 1792 [3]. His studies and professional carrier are connected with Kazan, next big town downstream Volga.

The first presentation of his "new geometry" took place at the Department of physical and mathematical sciences of the Kazan University on February 7, 1826. A formal application of the Department asking to publish his presentation entitled "Exposition succinte des princeples de la geometrie" (in French) was rejected by the local "Uchenye zapiski". The original manuscript was lost.

In 1827, N.I. Lobashevskii was elected Rector of the Kazan University.

The first publication of the new geometry is dated 1829, when "Kazanskii Vestnik" published Lobachevskii's "On the principles of geometry" (in Rus-

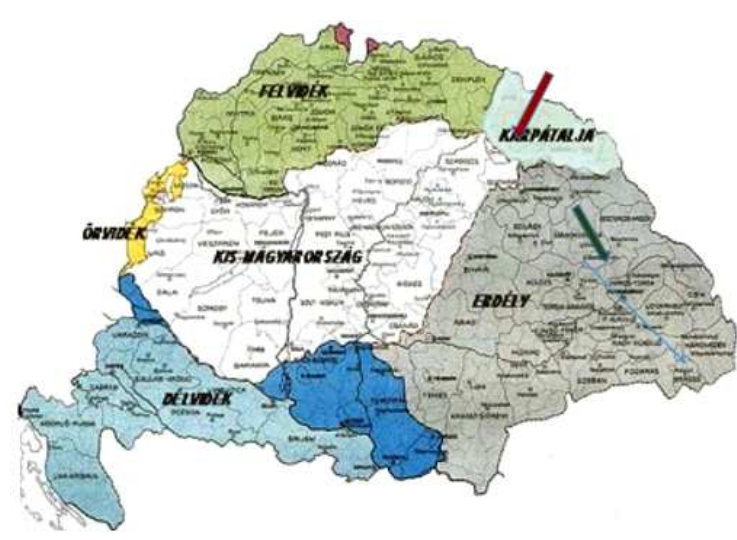

Fig. 3. Hungary of Bolyai's time. The solid arrow points to Bolyai's homeland, and the dotted arrow points to Uzhgorod (Ungvár), site of the first BGL meeting in 1997. Today's Hungary is in white

sian). In 1932, this paper was submitted to the Russian Academy of Sciences (in St. Petersburg). It was reviewed and rejected by M.V. Ostrogradskii, whose report was totally negative. Moreover, the magazine "Syn otechestva" published an ironic anonymous pamphlet in 1834 brutally criticizing the author of the new geometry.

These misfortunes did not discourage Lobachevskii. He continued writing and publishing, "Geometrishce Untersuchungen", in German, among others. Ultimately, one year before his death, ill and blind, he dictated his "Pangeometry", published in 1855 in Russsian, followed by the translation into French and publication in 1856. The Bolyais and Gauß became familiar with the "Geometrishce Untersuchungen". Farkas, in his book of 1851 and Gauß (in a private letter) appreciated and praised it, while the author was still alive. Nevertheless, Lobachevskii never received public recognition during his life. He died ill, on February 12, 1856, in misery.

\subsection{János Bolyai ${ }^{2}$}

was the youngest and maybe the most tragic personage among BGL. Born in Kolozsvár (1802), he moved in 1804 with his father Farkas to Marosvásárhely, both in Transylvania (now Rumania), see the map in Fig. 3.

2 In Hungarian, contrary to other European languages, the family name precedes the given name: Bolyai János. 
In 1818, Farkas asked his friend C. Gauß to support further studies of János at the Göttingen University. But, for some reason, Gauß was reluctant to do so. Consequently, János went to the Engineering Academy in Vienna. After graduation, he was appointed a custom officer in Temesvár.

In 1820, he informed his father that he found the way to prove Euclid's 5-th postulate. Farkas discouraged his son from doing something he considered hopeless.

Despite father's advise, János continued his efforts, and, in 1824, he found a mathematical relation between the length of a perpendicular and the angle of the asymptote. "I created a world from nothing", he exclaimed to his father. One can see from his manuscripts, sketches, and letters that, already in 1820, he was on the right track in considering the limit of the large circle. Most of the work done by János Bolyai remained unpublished. Manuscripts can be found [5] in libraries and museums, e.g., in Marosvásárhely.

In February 1825, János sent his manuscript to his farther. Farkas was unable to abandon the old geometry, whose proof took part of his life, in vain. Reluctant to follow the ideas of his son, he was looking for possible shortcomings in the work of János. Finally, in February 1829, he agreed to publish the results of his son as an appendix to his own book "Tentamen Juventutem...", a mathematical course for young people. The appendix (in Latin) was entitled "Appendix scientium spatii absloute veram exhibeus". The book appeared in 1831. A copy, immediately sent by Farkas to Gauß did not reach the recipient: the area was plagued by cholera. Another copy had reached the designation at the beginning of 1832 . Gauß reacted immediately, in March 1832. The response was fatal for János. "You may be surprised - he wrote that I will not praise your son's work since praising it would mean praising myself... his ideas almost coincide with my way of thinking during 30-35 years from now... Myself, I also intended to publish these results, but once my friend's son did it, I feel free from that duty". The above letter was preceded by another one, to Gerling in which Gauß praises János as a first-rank genius.

Gauß' letter to Farkas made happy the farther, but not his son. János suspected that his ideas were stolen. Furthermore, in 1848, he received Lobachevskii's "Geometrische Untersuchungen". He even sus- pected that "Lobachevskii" is a pseudonym used by Gauß as a mask. After the first shock and the resulting depression, he started critically reading Lobachevskii's work that was really very close in spirit to what János did.

Bolyais' native language, used in communication and correspondence, was Hungarian, although their scientific works were written in Latin or German. János was fluent also in Italian and French and was familiar with Chinese and Tibetian. He was working on the idea to reform the Hungarian language, aiming to adapt it to scientific texts. (NB: The precondition to a candidate to the Hungarian Academy of Sciences was a publication in Hungarian). He believed that Hungarian, due to its particular grammar, is a perfect basis for a future universal scientific language [6]. Its basis should be semantic (symbolic). János was obsessed with the so-called "root words" (gyökszavak) or homonimas, unique for the Hungarian. He argued so by comparing Hungarian with Latin and German, e.g., in the phrase:

\section{Péter ember}

\section{Petrus est homo}

Peter ist ein Mensch.

He was trying to fix, as in mathematics, ambiguities, i.e., to establish a one-to-one correspondence between words (symbols $=$ semiotics) and notions. There is, however, a controversy between simple words-symbols and the complicated Hungarian grammar (e.g., in conjugations and declinations). (See Ref. [6] for the further reading on this subject.) A relatively new development in this direction is connected with the use of modern communication means (computers, Internet, e-mail, etc.), where new (telegraphy) languages are being developed automatically (shorthand, neglect of accents, "likes", etc.).

János was also an excellent violin player and good fencer

His legacy consists of over 15000 pages of manuscripts, written in special codes, stored in the Teleky library in Marosvásárhely. Elemér Kiss contributed [5] largely to their de-codification. It is not always clear whether the texts imply shorthand-writing (stenography) or homonimas.

\section{Followers}

The next breakthrough came with the syntheses of non-Euclidean and differential geometry with surface theory, resolving the problem of uniqueness of the

ISSN 2071-0194. Ukr. J. Phys. 2019. Vol. 64, No. 11 
new geometry - the main obstacle on the way to its approval. Metrics, geodesics, curvature etc. provided classification and interpretation of the new geometry.

Berngard Riemann (1826-1866), with his 1854 inauguration lectures at the Göttingen University, published in 1854, introduces the notion of manifolds replacing the space, with points corresponding to elements of a manifold. The geometry of the manifold is defined by the squared distance between infinitesimally close points:

$d s^{2}=\sum_{i, j=1}^{n} q_{i j} d x_{i} d x_{j}$,

where $q_{i j}(x)$ is the metric tensor.

The above equation defines the Riemann metrics within the geometry of the Riemann space.

Geometries are classified according to their curvatures $K: K>0$ is called Riemann (or elliptic) geometry, $K=0$ is for the conventional Euclidean geometry, and $K<0$ corresponds to the non-Euclidean, BGL geometry.

Lorentz, Poincaré, Minkowski and Einstein contributed to making the new geometry a common physical language. The four-dimensional Lorentz space-time and the pseudo-Euclidean metrics

$d s^{2}=d x^{2}+d y^{2}+d z^{2}-c^{2} d t^{2}, \quad K=0$

form the basis of modern physics, in particular of the relativity theory, resulting, e.g., in the relation between mass and energy

$E=m c^{2}$,

with global consequences for the mankind.

Cosmology and the history of our Universe are also based on the new geometry. Soviet physicist A.A. Friedman (1888-1925) has found a special solution of the Einstein equation within the BolyaiLobachevskii metrics in 1922 and predicted the expansion (inflation) of our Universe confirmed in 1929 (Hubble).

The new geometry has enriched natural science conceptually, although the curvature effects are negligible within observable distances. Lobachevskii suggested tests based on the measured angular distances (parallax) of stars to the astronomer Struve. He proposed also the calculation of definite integrals on surfaces and volumes extended to infinity. About 200 integrals calculated in this way are available in textbooks and tables.

ISSN 2071-0194. Ukr. J. Phys. 2019. Vol. 64, No. 11

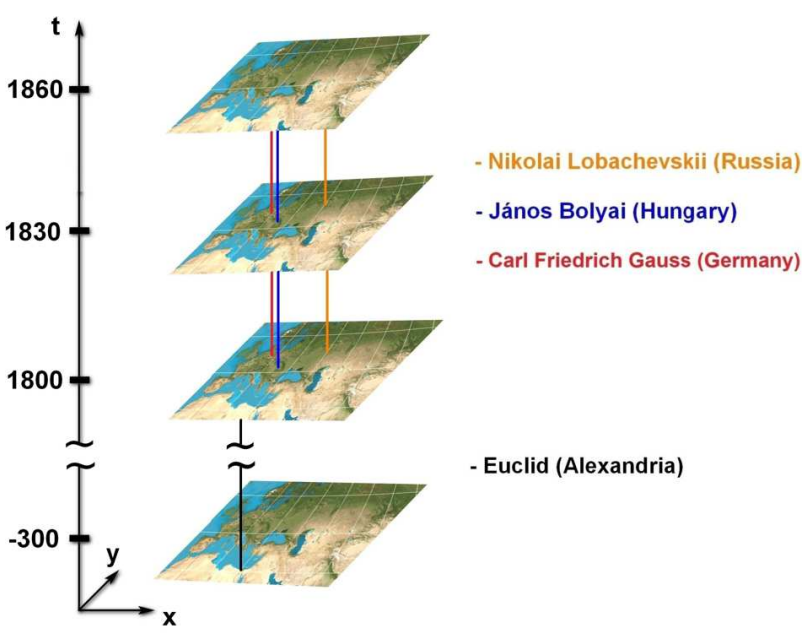

Fig. 4. Time geography: simplified (straightened) world lines of Euclid, János Bolyai, Gauß, and Lobachevskii. Their parallels never crossed

Interesting are applications in architecture using hyperbolic constructions, see [7].

A modern branch of the non-Euclidean geometry is connected with the so-called quantum groups or $q$-deformations.

\section{Epilogue}

The abrupt birth, at the same time but different places, of the new geometry, after thousands dormant years, seems almost a mystery. Mysterious is also the fate of its creators, thinking almost identically, while living at the same period on the same continent, without knowing about each other (see Fig. 4).

The BGL conferences usually include review talks and discussions on the history and biographies of Bolyai, Gauß, and Lobachevskii, their relation to teachers and followers. The priority of the discovery was never questioned at the conferences. All three deserve appreciation. Both János Bolyai and N.I. Lobachevskii, for various reasons, were unfortunate in failing to produce a timely open publication on their discoveries. However, this fact cannot justify any dispute on priorities. Gauß did not publish a single paper on non-Euclidean geometry, still his reputation is so high that nobody doubts that he "knew it". A rather unique situation in the history of science?! The alphabetic ordering of BGL at conferences was accepted from the very beginning of the series and was never questioned, which, however, did not prevent 
the speakers to have personal preferences and diverse points of view.

The previous BGL conferences were dominated by Hungarian and Ukrainian-Russian-Bielorussian organizers and participants, extended by wide international participation. Co-patriots of Gauß are welcome at future BGL meetings! The BGL series has a certain Middle European (Mittleuropäische) flavor enriched by participants from far-away countries. The next BGL conference will be held in Lviv (Western Ukraine) on July 4-9, 2021, visit: http://indico.bitp.kiev.ua/e/bgl-2021.

I had pleasure and profited very much from communication with participants of BGL meetings, where I knew famous personalities like A.N. Bogolyubov, outstanding expert in history of science, brother of Nikolai Nikolaevich, István Lovas, Elemér Kiss, and N.A. Chernikov and discovered new worlds such as Transylvania and the Volga area - hosts of BGL conferences and fertile birthplaces of great individuals.

$I$ thank the organizers of the present meeting for inviting me to present this talk.
1. https://indico.cern.ch/event/586799/page/8964-formerbgl-conferences .

2. L.L. Jenkovszky. BGL conferences: a brief history, Acta Physica Debrecina, TOMUS XLII, Redigid Zoltán Trócsányi, 2008.

3. Nikolai Ivanovich Lobachevskii (Kazan' University, 1979) (in Russian).

4. W.K. Bühler. Gauß. A Biographic Study (Springer, 1981).

5. K. Elemér. Matematikai Kincsek Bolyai János Kéziratai Hagyatékaibol (Akadémiai kiadó, 1999) (available also in English).

6. Marácz Sándor, Bolyai János és a Magyar Mint Tökéletes Nyelv. http://kincseslada,hu/magyarsag/content.php?article.328.

7. https://indico.cern.ch/event/586799/contributions/2695991/ attachments/1512907/2359928/Jenkovszky.pdf .

Л.Л. Єнковсъкий

Received 10.09.19

\section{ВІД ЕВКЛІДА ДО БГЛ}

$\mathrm{P}$ е $з$ ю м е

Поява нової неевклідової геометрії Бояі, Гауса і Лобачевського (БГЛ) та її вплив на сучасну науку стала предметом вивчення серії дворічних конференцій. В цій роботі я коротко нагадую її історію. 